\title{
GEOTEHNIČKI USLOVI IZGRADNJE BAZNE STANICE U NASELJU LAZAREVO, FOČA
}

Đurić N. ${ }^{1}$

UDK: $621.395 .721 .5: 550.8(497.6 \mathrm{FOČA})$

DOI:10.14415/konferencijaGFS 2016.052

Rezime: Bazne stanice za mobilnu telefoniju, uglavnom su raspoređene na vrhovima brežuljstih ili brdsko-planinskih terena. Ponekad se mogu naći i u padinskom dijelu, bliže godnjem dijelu padine, ukoliko se signalom pokriva samo naseljeni dio u njenom podnožju. Takva stanica je predviđena na području opštine Foča, koja će se nalaziti južno od gradskog naselja u nižem dijelu padine, planine Plijěs sa nagibom prema naseljenim mjestima opštine.

Lokacija se odabrana tako da može pokrivati signalom predviđeno područje, ali i da ima pristup lokalnim putevima. Za izgradnju stanice potreban je manji prostor, ali je u ovakvim sredinama neophodno istražiti širi prostor terena koji može da ima uticaja na njegovu stabilnost, tokom i nakon izgradnje objekta.

Ključne riječi: teren, bazna stanica, padina, stabilnost, sredina

\section{UVOD}

Izgradnja bazne stanice na padinskom dijelu planine Pliješ, zahtijevala je sagledavanje karakteristika terena sa aspekta mogućnosti temeljenja objekta koji se sastoji od antenskog stuba visine $25,0 \mathrm{~m}$. Odabrana lokacija je u srednjem, djelimično bliže donjem dijelu padine navedene planine, čija je prirodna stabilnost djelimično narušena prisustvom individualnih stambenih objekata i lokalih puteva.

Generalno posmatrano padina je uslovno stabilna sa mogućnošću narušavanja njene stabilnosti tokom određenih inženjerskih aktivnosti na terena. Prisustvo individualnih objekata, kao i značaj bazne stanice, obavezuju kvalitetnije proučavanja terena neposredne lokacije i šire okoline, a sve sa ciljem uklapanja budućeg objekta u prostornu realnost, njegovu funkcionalnost. Karakteristike padine, litološki sastav i vrsta objekta, odredili su način istraživanja terena, laboratorijska ispitivanja i analizu dobivenih podataka, koji su podloga za definisanje geotehničkih uslova temeljenja.

\section{OSNOVNE KARAKTERISTIKE TERENA}

Lokacija objekta se nalazi na donjem dijelu padine planine Pliješ, na veoma uskom dijelu terena gdje se spajaju dva lokalna puta, slika 1. Neposredna okolina predstavlja

\footnotetext{
${ }^{1}$ Prof. dr Neđo Đurić, Univerzitet u Novom Sadu, Građevinski fakultet Subotica, Kozaračka 2a, Srbija. e.mail.nedjodjuric10@g.mail.com
} 
Contemporary achievements in civil engineering 22. April 2016. Subotica, SERBIA

blago ustrmljenu padinu sa padom orjentisanim u pravcu sjever - sjeveroistok, odnosno azimutom od oko $30^{0}$. Nagib padine je oko $10-20 \%$, odnosno padnim uglom oko $9^{0} \mathrm{u}$ blago ustrmljenim i $18^{0}$ u ustrmljenim dijelovima. Padina je uslovno stabilna, što se vidi po savremenim kretanjima njenog površinskog dijela i prisustvom ožiljaka klizišta lokalnog karaktera. Na padini se nalaze indivdualni stambeni objekti, koji su u podsijecanom dijelu padine štićeni potpornim zidovima i manjim kanalima i drenažama za prihvatanje površinskih i podzemnih voda [1].

Posmatrano u cjelini, sve to čini jednu poboljšanu prirodnu konstrukciju pripovršinskog dijela terena u dijelu prisustva objekata. Često se između objekata pojavljuju plitka lokalna klizišta, koja narušavaju uslovnu stavilnost padine. Ipak se i ti dijelovi padine privode uslovnoj stabilnosti sa izgradnjom novih objekata, jer se prethodno saniraju, poboljšavajući kontinuitet stabilnosti njenog šireg prostora.

U geološkoj građi šireg dijela padine učestvuju naslage donjeg karbona $\left(\mathrm{C}_{1}\right)$, sedimenti permotrijasa $(\mathrm{P}, \mathrm{T})$ i deluvijalni $(\mathrm{d})$ sedimenti $[1,2]$.

Naslage donjeg karbona $\left(\mathrm{C}_{1}\right)$ izgrađuju hipsometrijski niže i sredne dijelove padine (na kojima je situirana i neposredna lokacija). U bazi se nalaze jedri i tabličasti pješčari preko kojih su istaloženi filitični škriljci, a zatim tabličasti jedri pješčari sa rjeđim proslojcima glinaca. Generalno zaliježu u pravcu sjeveroistoka, sa azimutom pada oko $73-77^{0}$, pod uglom koji se kreće u rasponu od $25-35^{0}$.

Hipsometrijski više horizonte padine, jugozapadno od istraživane lokacije izgrađuju permotrijaske $(\mathrm{P}, \mathrm{T})$ naslage, diskordantno istaložene preko sedimenata paleozoika. Predstavljene su crvenim kvarcnim konglomeratima, pješčarima i škriljcima. Slojevi ovih sedimenata generalno zaliježu u pravcu jugoistoka sa azimutom pada oko $115^{0} \mathrm{i}$ pod uglom oko $40^{\circ}$.

Na središnjim i nižim horizontima padine površinu terena prekrivaju deluvijalne naslage nastale prenošenjem raspadnutog materijala stijena substrata terena u hipsometrijski niže i blaže ustrmljene dijelove padine dejstvom gravitacije i vodama nekanalisanih tokova iz atmosverskog taloga. Izgrađuje ih drobina pješčara, sivih glinaca i filitičnih škriljaca, veličine zrna u rasponu od milimetarskih dimenzija do blokova maksimalnih dimenzija oko 500,0 mm. Preovlađuju zrna veličine od 10,0 $\mathrm{mm}$ do 200,0 mm. Međuprostor je zapunjen glinovito pjeskovitom ispunom koja nema veća vezivna svojstva u prirodnom stanju. Površinski dio je humuziran $[3,4]$.

U tektonskom pogledu istraživana lokacija i njena šira okolina pripadaju geotektonskoj jedinici ,Zona paleozojskih škriljaca i mezozjskih krečnjaka, odnosno strukturno facijalnoj jedinici Prača-Foča, tektonska jedinica Ustikolina.

Detaljnije posmatrano, padina iznad bazne stanice je obrasla šumom sa visokim stablima, a ispod su obrađene poljoprivredne površine. U prirodnim uslovima teren je optimalno povoljan, ali se on već ne nalazi u stvarnim prirodnim uslovima. Iznad i ispod bazne stanice padina je djelimično usječena usljed izgradnje lokalnih puteva, gdje nisu uređeni kanali za prihvatanje površinskih voda.

Stijene koje izgrađuju dublje dijelove terena u bližoj i široj okolini, prema svojim filtracionim karakteristikama predstavljaju nepropustljive stijene i imaju funkciju hidrogeoloških izolatora. Procjeđivanje vode u horizontalnim i vertikalnim pravcima moguće je samo duž pukotina i sedimentima površinske raspadine, koja je djelimično konsolidovana $[1,3,4]$. Na predmetnoj lokaciji nema karakterističnih hidrogeoloških pojava na površini terena. U neposrednoj okolini odnodno u donjem dijelu padine 
protiče rijeka Čehotina koja predstavlja glavni kolektor kojem gravitiraju svi stalni i povremeni površinski i podzemni tokovi.

Prema MSK - 64 skali uže područje neposredne lokacije, kao i njena bliža i šira okolina krakterišu:

- područje sa maksimalnim intezitetom očekivanih zemljotresa $6^{0}$ i vjerovatnosti pojave $63 \%$ za povratni period od 50 godina

- područje sa maksimalnim intezitetom očekivanih zemljotresa $7^{0}$ i vjerovatnosti pojave $63 \%$ za povratni period od 100 godina.

Detaljnija proučavanja lokacije pored prikupljanja podataka rekognosciranjem i kartiranjem terena uže i šire okoline, zahtijevala su izradu jednog istražnog rada do dubine čvrstih stijena. Urađen je raskop dubine $5,0 \mathrm{~m}$, snimljen otvoreni profil terena i uzeti uzorci stijena za laboratorijska ispitivanja. Površinski dio terena je izgrađen od raspadnutih stijena glinovito pjeskovito drobinastih materijala, gdje su valutice stijena nepravilnog oštro ivičastog oblika, veličine od nekoliko $\mathrm{mm}$, do komada preko $50,0 \mathrm{~cm}$. Tokom izrade raskopa mašinskim putem, koji se nalazi na strmom dijelu padine, praćen je način i ponašanje zidova raskopa tokom njegove izrade sa dubinom. Na otvorenom profilu raskopa do dubine istraživanja, detaljnije su prikupljanji podaci o karakteristikama materijala koji izgrađuju teren kao što su litološki sastav, litostratigrafski sklop, elementi zalijeganja slojeva, ispucalost stijena, karakter pukotina i oštrina ivica komada stijene. Nije registrovano prisustvo podzemnih voda.

$\mathrm{Na}$ osnovu istražnih radova na terenu i rezultata laboratorijskih ispitivanja sagledana je geološka građa i rasčlanjeni slojevi. Geomehaničke karakteristike sa prikazom graničnih vrijednosti parametara date su za slojeve u kojima su vršena terenska ili laboratorijska ispitivanja.

\section{ANALIZA GEOTEHNIČKIH USLOVA}

Za analizu geotehničkih uslova detaljno je analizirana konstrukcija terena u odnosu na litološke tipove tla, njihov položaj u sklopu proučavane dubine terena, kao i njihov međusobni položaj, zatim njihovo stanje, sastav, inženjerskogeološke i hidrogeološke karakteristike, te fizičko - mehaničke osobine i otporno - deformabilne karakteristike. U svrhu detaljnog sagledavanja konstrukcije terena, na osnovu rezultata terenskih i laboratorijskih istraživanja i ispitivanja urađen je grafički prikaz profila terena, slika 1 .

Teren istraživane lokacije, kao i bližu okolinu do dubine istraživanja, 5,0 m, izgrađuju sedimenti - litološki članovi različitih fizičko - mehaničkih i otporno - deformabilnih karakteristika. Detaljnom analizom njihovih parametara, svi se mogu svrstati u nekoliko sredina unutar kojih se u uslovima opterećenje odnosno rasterećenje, ponašaju istovjetno ili slično. Izdvojene su dvije sredine.

Sredina 1, predstavlja kompleks sedimenata deluvijalnog depozita sa karakteristikama sipke sredine. Sredinu dominantno izgrađuje drobina pješčara, glinaca i filitičnih škriljaca amorfnog oblika odlomaka blijedo sive do sive boje, veličina zrna od milimetarskih dimenzija do blokova veličine i do 500,0 mm. U ukupnoj masi blokovi maksimalnih dimenzija učestvuju do $10 \%$. Ivice odlomaka su oštre,a pojedina zrna su djelimično zaobljenih ivica. Međuprostor je zapunjen glinovito pjeskovitom ispunom 
Contemporary achievements in civil engineering 22. April 2016. Subotica, SERBIA

žuto smeđe boje. U prirodnom stanju ispuna nema vezivna svojstva. Sloj je registrovan istražnim raskopom na dubini od $0,30 \mathrm{~m}$ do $3,00 \mathrm{~m}$. Kroz međuprostor između odlomaka vrši se veoma brzo procjeđivanje atmosferskih i podzemnih voda $u$ vertikalnom $i$ horizontalnom pravcu, odnosno u pravcu nižih horizonata padine. U prirodnom stanju predstavlja stabilnu, nestišljivu do malo stišljivu sredinu velike nosivosti. Zasijecanjem kao i prodorom vode iz viših horizonata padine remeti mu se stabilnost i prelazi u uslovno stabilnu do nestabilnu sredinu. Na geotehničkom presjeku terena, slika 1, sredina je označena brojnom oznakom 2 i geomehaničkom oznakaom $\mathrm{DE}_{1}$ (debris).

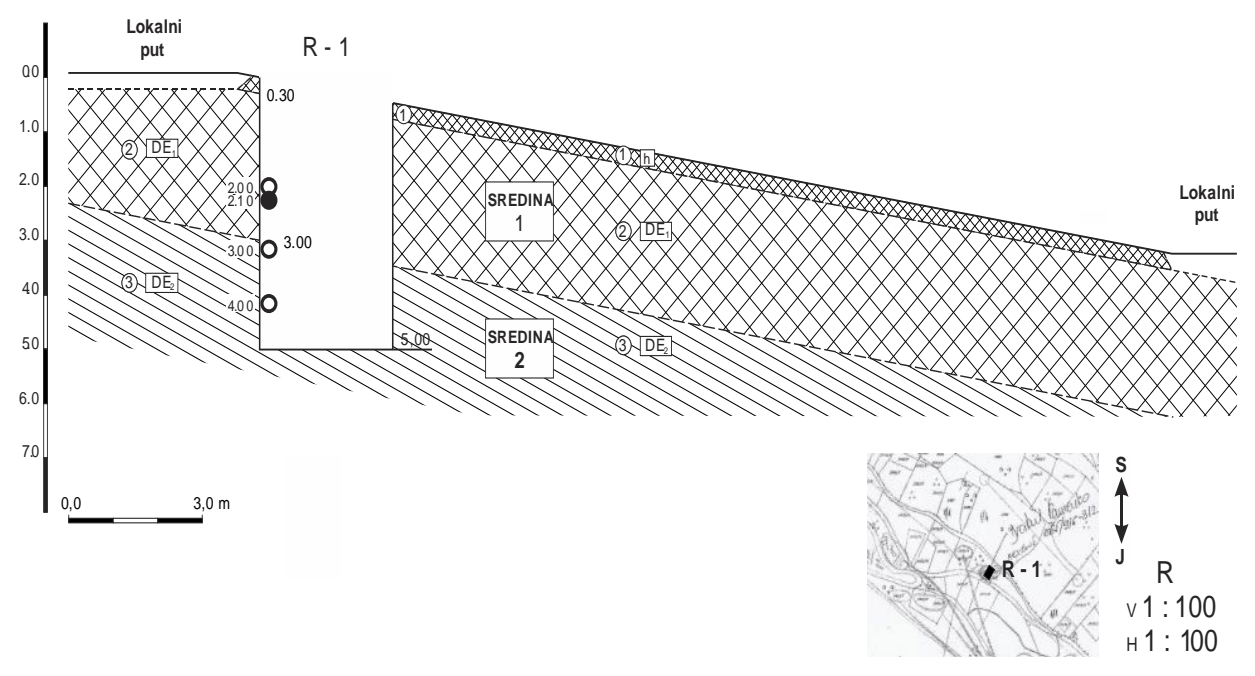

Slika 1. Geotehnički presjek terena

1. humus, 2. Deluvijalni depozit $D E_{1}$, 3. kora raspadanjasubstrata terena $D E_{2}$

Sredina 2 je prelazna zona između deluvijalnih sedimenata i substrata terena, koju izgrađuju sedimenti kore trošenja nastali degradacijom površine paleoreljefa substrata terena. Predstavljena je drobinom pješčara, rjeđe glincima i filitičnim škriljcima. Odlomci su pločastog oblika, preovlađujuće veličine komada oko 200,0 mm. Međuprostor je zapunjen ispunom od glinovito pjeskovitog materijala koji u prirodnom stanju nema vezivna svojstva. Sloj je registrovan istražnim raskopom na dubini od 3,00 $\mathrm{m}$. Krajnja dubina sloja nije dostignuta do dubine istraživanja 5,00 m. Kao i u povlatnom sloju kroz međuprostor između odlomaka vrši se procjeđivanje atmosferskih i podzemnih voda u vertikalnom i horizontalnom pravcu, odnosno u pravcu nižih horizonata padine. U prirodnom stanju predstavlja stabilnu, nestišljivu sredinu velike nosivosti. Zasjecanjem kao i prodorom vode iz viših horizonata padine remeti mu se stabilnost i prelazi u uslovno stabilnu do nestabilnu sredinu. Na geotehničkom presjeku terena označena je brojnom oznakom 3 i geotehničkom oznakom $\mathrm{DE}_{2}$ (debris).

Otporno - deformabilna svojstva čvrstih stenskih masa, zavise od prisustva i karakteristika mehaničkih diskontinuiteta u njima duž kojih može u potpunosti odsustvovati sila kohezije. Značajna razlika u čvrstoći, zbog toga postoji između monolitnih djelova mase $i$ realnog stjenskog masiva, kao $i$ između različitih varijeteta $i$ litoloških članova, te njihovih mehaničkih diskontinuiteta $[5,6]$. 
Савремена достигнућа у грађевинарству 22. април 2016. Суботица, СРБИЈА

Izbor parametara mjerodavnih za geostatičke proračune izvršen je na osnovu:

- rezultata laboratorijskih ispitivanja uzoraka tla i čvrstih stijena, vodeći računa o stepenu njihove reprezentativnosti i uslovima ispitivanja [7]

- podataka o realnim svojstvima stijenskih masa kompleksa drobine (litološka heterogenost, veličine i oblika odlomaka, karakteristika materijala ispune i dr.)

- postojećih empirijskih korelacionih veza između fizičko-mehaničkih svojstava, strukturnih svojstava i rejtinga stijenske mase (Analysis of Rock/Soil Strength using RocLab), slika 2.
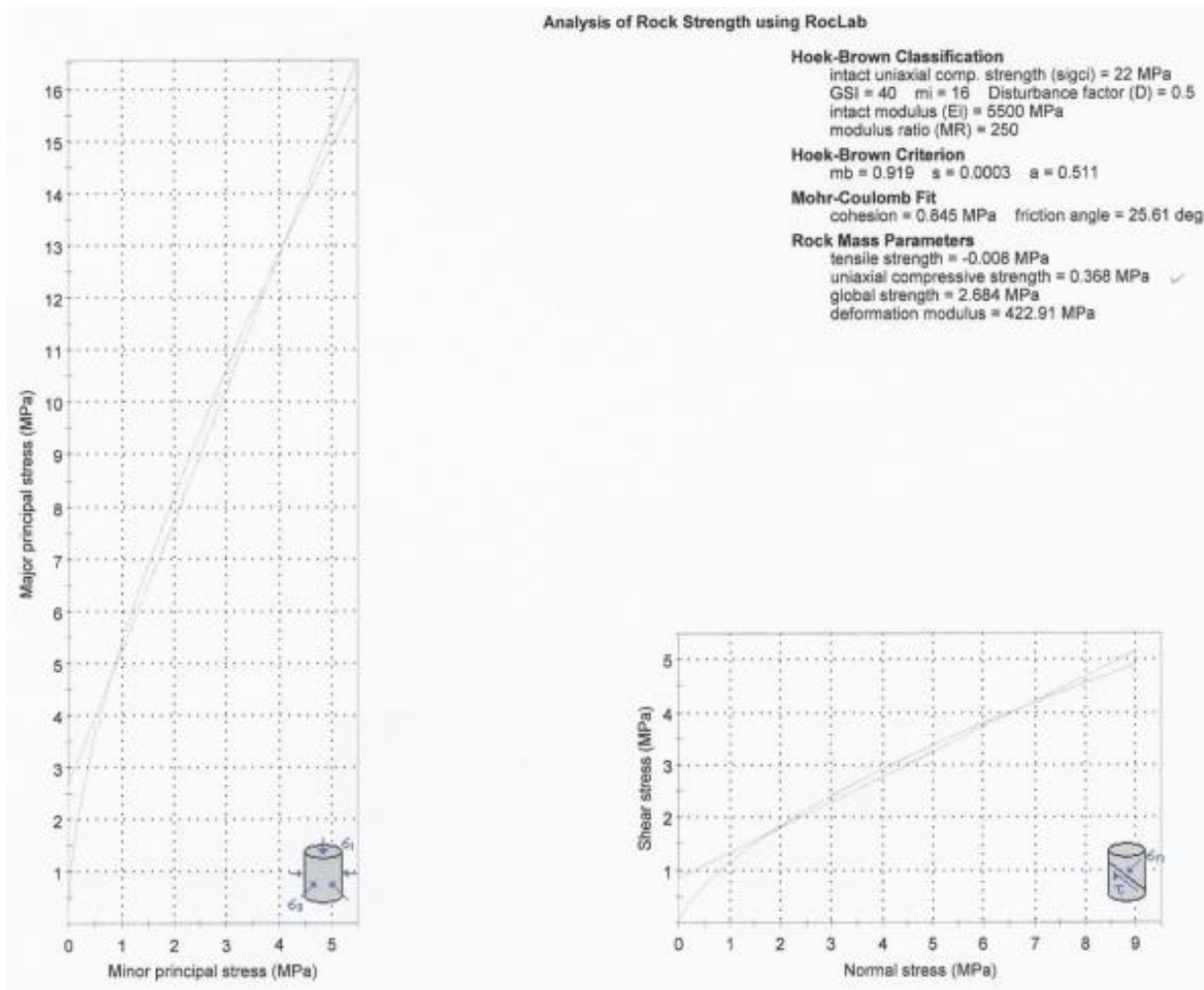

Slika 2. Rezultati analize upotrebom programa RocLab za sredinu $D E_{2}$

Usvojeni parametri za geostatičke proračune, za pojedine sredine, dati su u tabeli 1 .

\section{DISKUSIJA}

Nagib padine na kojoj će se graditi bazna stanica je $10-20 \%$, što se prema morfološkim svojstvima može vrednovati kao uslovno povoljan teren. Sa geotehničkog aspekta tereni koji imaju dozvoljeno opterećenje $>300 \mathrm{kN} / \mathrm{m}^{2}$ spadaju u terene povoljne stabilnosti, ukoliko su ostali faktori kao što su raspadnutost ili ispucalost stijena, nagib padine $\mathrm{i}$ 
Contemporary achievements in civil engineering 22. April 2016. Subotica, SERBIA

slojeva, kao i ostali uticajni faktori povoljni $[3,5,6,8]$. Uticaj geodinamičkih svojstava vezan je za moguću pojavu klizišta, kako u dijelu padine iznad i ispod bazne stanice. Prema sadašnjem stanju terena nema registrovanih pojava klizišta, niti erodovanja površine terena. Površinska voda brzo odlazi niz padinu, a manji dio se infiltrira $u$ podzemlje, koja kroz relativno propusne sedimente površinsko raspadnutog dijela odlaze u hipsometrijski niži dio terena prema vodotoku Čehotine.

Tabela 1. Usvojene vrijednosti parametara za geostatičke proračune

\begin{tabular}{|c|c|c|}
\hline \multicolumn{3}{|c|}{ Sredina $1\left(D^{2} E_{1}\right)$} \\
\hline \multirow[t]{2}{*}{ Parametri } & \multicolumn{2}{|c|}{ Usvojene vrijednosti } \\
\hline & Intaktna stijena & Preračunato na RocLab \\
\hline čvrstoča na pritisak $-\sigma(\mathrm{MPa})$ & 18,00 & 1.100 \\
\hline ugao unutrašnjeg trenja $-\varphi\left({ }^{0}\right)$ & & 17,0 \\
\hline kohezija - c (MPa) & & 0,400 \\
\hline $\begin{array}{l}\text { modul elastičnosti dinamički }-\mathrm{E}_{\text {din }} \\
(\mathrm{MPa})\end{array}$ & 36.000 & \\
\hline zapreminska težina $-\gamma\left(\mathrm{kN} / \mathrm{m}^{3}\right)$ & & 5,60 \\
\hline \multicolumn{3}{|c|}{ Sredina $2\left(\mathrm{DE}_{2}\right)$} \\
\hline čvrstoča na pritisak $-\sigma(\mathrm{MPa})$ & 21,55 & 2.684 \\
\hline ugao unutrašnjeg trenja $-\varphi\left({ }^{0}\right)$ & & 25,0 \\
\hline kohezija - c (MPa) & & 0,800 \\
\hline $\begin{array}{l}\text { modul elastičnosti dinamički }-\mathrm{E}_{\mathrm{din}} \\
(\mathrm{MPa})\end{array}$ & 42.500 & \\
\hline zapreminska težina $-\gamma\left(\mathrm{kN} / \mathrm{m}^{3}\right)$ & \multicolumn{2}{|c|}{26,00} \\
\hline
\end{tabular}

Prisutna ispucalost stijena u dijelu mikrolokacije objekta smanjuje nosivost stijena $u$ odnosu na njihovu kompaktnost. Takođe moguća su diferencijalna slijeganja u zavisnosti od nagiba slojeva pješčara. Kod temeljnog iskopa će se mijenjati naponsko deformaciono stanje unutar stijenske mase, što će zavisiti od od stepena ispucalosti stijena u dijelu temeljenja objekta $[6,8,9,10]$. Stepen istraženosti nije u dovoljnoj mjeri primijenjen, jer se nisu poznavali podaci o gabaritima objekta u horizontalnom smislu, način temeljenja objekata i ukupno opterećenje.

Sagledavanjem inženjerskogeoloških karakteristika terena, koje su poslužile kao osnov za izbor određenih podataka iz literature, te rezultata laboratorijskih ispitivanja, dobivene vrijednosti su korištene za određivanje dozvoljene nosivosti stijena za temelj u sredini dva (2) drobina pločastih oblika odlomaka $\mathrm{DE}_{2}$. Usvojena vrijednost jednoaksijalne pritisne čvrstoće $21,55 \mathrm{MN} / \mathrm{m}^{2}$, predstavlja slabe do srednje čvrste sedimentne stijene prema ISRM. Na osnovu terensko-laboratorijske identifikacije i približne vrijednosti jednoaskijalne pritisne čvrstoće to su stijene između grupe R2 (slaba stijena) i R3 (srednje čvrsta stijena ) prema ISRM [6,8].

Dobivena vrijednost nosivosti stijena oko $450 \mathrm{kN} / \mathrm{m}^{2}$, pokazuje da je nosivost $\mathrm{u}$ granicama dopuštene nosivosti stijena pješčari sa proslojcima filitičnih škriljaca, koja se 
prema Krahenbuhlu i Wagneru, za raspadnute strukture povoljne stabilnosti kreće u granicama od $350-600 \mathrm{kN} / \mathrm{m}^{2}$. Prema Sinhg-u i Mehrotr-u procjena dopuštene nosivosti stijena na bazi geomehaničke klasifikacije Bieniawskog (RMR), stijene se nalaze u klasi IV, loše stijene, gdje dopuštena nosivost $1350-450 \mathrm{kN} / \mathrm{m}^{2}$. Prema klasifikaciji stijena po čvrstoći na pritisak, stijene spadaju u grupu mekih stijena $\sigma<50$ $\mathrm{MN} / \mathrm{m}^{2}$, razvrstane u klasu 2, čvrstoće $15-50 \mathrm{MN} / \mathrm{m}^{2}$, umjereno čvrste stijene $[6,8,9]$. Čvrstoća na pritisak intaktne stijene preračunata na RocLab, odnosno čvrstoću stijene u prirodnom masivu, iznosi $2.684 \mathrm{MPa}$, Geološki indeks čvrstoće GSI 40, a komstanta $\mathrm{m}_{\mathrm{i}}$ 16 kaarkteriše srednjezrne do finozrne sedimentne stijene. Prema navedenim veličinama po Bieniawskom 1989, stijene sredine dva (2) karakterišu blokovska uglasta oštećenja sa prisustvom mnogobrojnih puktina, gdje su blokovi orjentisani u pravcu slojevitosti, a zidovi pukotina su prilično dobri, što ih svrstava u srednje stanje kvaliteta $[6,8]$.

Za temeljenje objekta bazne stanice odabrati dubinu ispod 3,0 m na hipsometrijski nižoj koti, koja će biti dovoljna da obezbijedi stabilnost objekta u odnosu na njegovu visinu, karakteristike padine, susjednih objekata, uticaja mraza, kao i ostale specifičnosti vezane za objekte na ovakvim terenima $[9,11,12]$. Obzirom na sklonost stijena zarušavanju tokom iskopa za potrebe temeljenja, neophodno je osigurati zidove otvorene jame.

Obzirom na smjenjivanje stijenskog materijala na malom prostoru, kako po vertikali, tako i horizontali, neophodno je detaljno pratiti geološki sastav i katakteristike raspadine, odnosno ispucalog stijeskog materijala. Ukoliko se na otvorenoj površini temeljenja pojave čvrste stijene i mekana raspadina, potrebno je raspadnuti materijal zamijeni, drugim materijalom i izvršiti njegovo zbijanje, tako da odgovara približno prirodnim karakteristikama sredine 2.

\section{LITERATURA}

[1] Elaborat o geomehaničkim karakteristikama terena za potrebe izgradnje Bazne stanice u naselju lazarevo, opština Foča. FSD Tehničkog instituta Bijeljina. 2015.

[2] Osnovna geološka karta SFRJ, R 1:100000, list Foča. Savezni geološki zavod, Beograd. 1980.

[3] Sunarić, D. Klizišta i odroni u gornjem toku Drine. Rudarsko - geološki fakultet Beograd. 2000.

[4] Djuric, N., Djujic, A. Geological evaluation of the state of the route M18, section Foca - Hum, Republiuc of Srpska. Bijeljina. 2015. Arhives for Technical Sciences, 12, pp. 1-8.

[5] Rokić, Lj. Fizička geologija. Ljubomir Rokić. Sarajevo. 2011.

[6] Đurić, N. Hidrogeološka i inženjerskogeološka istraživanja. Građevinski fakultet Subotica, Tehnički institut Bijeljina. 2011.

[7] Eurocode 7. Geotechnical desing - Part 2: Desing assisted by laboratory testing, and Part 3: Desing assisted by fieldtesting. European Commitete for standarization. Brussels. 1997.

[8] Đukić, B.D. Geotehničke klasifikacije za površinske radove u rudarstvu $i$ građevinarstvu. Rudarski institut Tuzla. 2004.

[9] Stević, M. Mehanika tla i stijena. Rudarsko-geološki fakultet Tuzla. 1991.

[10] Sijerčić, I. Inženjerska geodinamika. IN SCAN d.o.o Tuzla. 2012. 
Contemporary achievements in civil engineering 22. April 2016. Subotica, SERBIA

[11] Nonveiller, E. Slipping stabilization and slopes. School book, Zagreb. 1987.

[12] Ćorić, S. Geostatički proračuni, treće izdanje. Rudarsko-geološki fakultet Beograd. 2008.

\section{GEOTECHNICAL CONDITIONS FOR THE CONSTRUCTION OF BASE STATION IN VILLAGE LAZAREVO, FOCA}

Summary: Base stations for mobile telephony, are mainly distributed on the tops of hilly or mountainous terrains. Sometimes they can be found also in slopes, closer to the upper part of the slope, if the signal covers only inhabited part in its base. Such station would be designed in the municipality of Foca, which will be located south of the urban settlement in the lower part of the slope, of mountain Plijes with an inclination towards the populated areas of the municipality.

The location was selected so that the signal can cover the anticipated area, but also to have access to local roads. The construction of the station takes less space, but in areas like this it is necessary to explore the wider space of the field that can have an impact on its stability during and after construction.

Keywords: field, base station, slope, stability, area 